\title{
Climate Specific Thermomechanical Fatigue of Flat Plate Photovoltaic Module Solder Joints
}

\author{
Nick Bosco, Timothy J Silverman and Sarah Kurtz \\ National Renewable Energy Laboratory, 15013 Denver West Parkway \\ Golden, CO 80401-3305 USA
}

\begin{abstract}
FEM simulations of PbSn solder fatigue damage are used to evaluate seven cities that represent a variety of climatic zones. It is shown that the rate of solder fatigue damage is not ranked with the cities' climate designations. For an accurate ranking, the mean maximum daily temperature, daily temperature change and a characteristic of clouding events are all required. A physics-based empirical equation is presented that accurately calculates solder fatigue damage according to these three factors. An FEM comparison of solder damage accumulated through service and thermal cycling demonstrates the number of cycles required for an equivalent exposure. For an equivalent 25-year exposure, the number of thermal cycles $\left(-40^{\circ} \mathrm{C}\right.$ to $\left.85^{\circ} \mathrm{C}\right)$ required ranged from roughly 100 to 630 for the cities examined. It is demonstrated that increasing the maximum cycle temperature may significantly reduce the number of thermal cycles required for an equivalent exposure.
\end{abstract}

Key Words: Photovoltaic Reliability, Solder Fatigue, Acceleration Factor, Thermal Cycling

\section{INTRODUCTION}

Solder joints that attach stringing ribbons to cells within a PV module will experience thermomechanical fatigue with outdoor exposure. Increasing thermomechanical fatigue will cause these joints to first crack and then ultimately fail. This PV module degradation mechanism will manifest as a loss of power due to a series resistance increase and, in the extreme case, total power loss due to an open circuit [1]. The rate of thermomechanical fatigue within these joints depends on several factors such as module design, materials selection and exposure conditions [2].

The purpose of this paper is to examine the specific weather characteristics that drive solder fatigue damage and to quantify how much this damage may vary with climate zone and specific deployment location. This work is motivated by a recent survey of PV module degradation made across India [3]. In this survey, modules that showed visible degradation upon inspection were further examined for their electrical characteristics. The survey showed that modules deployed in the hot climates exhibited power degradation due to an increase in series resistance, while the modules deployed in the cooler climates had a lower degradation in power that was not significantly influenced by a series resistance increase. A similar observation of modules deployed in hot climates exhibiting larger power degradation due to an increase in series resistance was also reported by Jordan et al. who examined more than 2000 PV degradation rates quoted in publications for locations around the world [4]. Because failing solder joints will result in an increase in series resistance, they proposed this as a possible mechanism for the higher degradation rates of the modules deployed in hotter climates.

We begin this work by developing a finite element model (FEM) of a flat plate module to calculate the accumulation of inelastic strain energy density (damage) within the solder joint through exposure to a temperature history. Simulations are then run to calculate the accumulation of solder damage both when the module is deployed in specific cities across a range of climatic zones and through accelerated thermal cycling. Simulations of one year in seven cities are conducted, and the solder damage accumulated is directly compared to a variety of accelerated thermal cycles. Finally, an empirical equation is presented that calculates solder damage for the modeled module based on simple, specific weather characteristics.

\section{METHODS}

\section{Cities}

We chose seven cities to evaluate in this study. They include Chennai and Bhogat in India and Golden Colorado, Phoenix and Tucson Arizona, Sioux Falls South Dakota and Honolulu Hawaii all in the United States. These cities were chosen because they represent a variety of climate zones and possess weather- 
monitoring sites that collect high-resolution meteorological data available for our analysis. Table I presents these cities and their climatic zones according to the criteria followed in the All-India Survey, Table II. These criteria define five climatic zones by their mean monthly maximum temperature and mean relative humidity. The five climatic zones include Hot and Dry, Hot and Humid, Temperate, Cold and Composite. Because solder fatigue is not directly influenced by humidity, only temperature was considered for this study.

Table I

\begin{tabular}{llc}
\hline city & climate & $\begin{array}{c}\text { mean monthly } \\
\text { max temp (C) }\end{array}$ \\
\hline Phoenix & Hot and Dry & 38 \\
Chennai & Hot and Humid & 37 \\
Tucson & Hot and Dry & 36 \\
Bhogat & Hot and Humid & 35 \\
Honolulu & Hot and Humid & 31 \\
Golden & Temperate & 27 \\
Sioux Falls & Cold & 23 \\
\hline
\end{tabular}

Table II

\begin{tabular}{lll}
\hline climate & $\begin{array}{c}\text { mean monthly } \\
\max \text { temp }(\mathrm{C})\end{array}$ & $\begin{array}{c}\text { mean relative } \\
\text { humidity }(\%)\end{array}$ \\
\hline Hot and Dry & $>30$ & $<55$ \\
Hot and Humid & $>30$ & $>55$ \\
& $>25$ & $>75$ \\
Temperate & $25-30$ & $<75$ \\
Cold & $<25$ & All values \\
Composite & when 6 months or more do not fall \\
& within any of the above categories \\
\hline
\end{tabular}

\section{FEM Model}

A 2D cross-sectional model of a generic crystalline silicon flat plate module was generated using COMSOL. The 2D simplification was made to produce a model capable of simulating years of weather exposure within a reasonable computational time. Because of the large aspect ratio of the PV module, the plane strain condition imposed by the $2 \mathrm{D}$ simplification is a reasonable approximation and yields a model that accurately captures the physics of solder behavior within the module. The module laminate was modeled to have 12 cells along its length and a glass/polymer backsheet construction as detailed in Figure 1 and Table III. The glass front sheet is $3.6 \mathrm{~mm}$ thick, the silicon cells $175 \mu \mathrm{m}$ thick with $150 \mu \mathrm{m}$ copper ribbons attached with $30 \mu \mathrm{m}$ of PbSn eutectic solder and encapsulated in $450 \mu \mathrm{m}$ of EVA. The backsheet was modeled as a single $175 \mu \mathrm{m}$ layer with elastic properties representing the appropriate contribution of its laminate's components. This simplification was made to increase the minimum model element thickness. The rate-dependent creep behavior and the time-independent plasticity of the solder were characterized by Anand's model [5]. All other materials were modeled as linear-elastic, with properties as detailed in Table III.

Table III

\begin{tabular}{lcccc}
\hline Material & $\begin{array}{c}\text { Thickness } \\
(\mathrm{mm})\end{array}$ & $\begin{array}{c}\text { Young's Modulus } \\
(\mathrm{GPa})\end{array}$ & CTE $\left(10^{-6} / \mathrm{K}\right)$ & $\begin{array}{c}\text { Poisson's } \\
\text { Ratio }\end{array}$ \\
\hline glass & 3.60 & 73.1 & 9 & 0.17 \\
silicon & 0.175 & 170 & 2.6 & 0.28 \\
copper & 0.150 & 110 & 17 & 0.35 \\
backsheet & 0.175 & 3.2 & 150 & 0.40 \\
60Sn40Pb & 0.03 & 10 & 21 & 0.40 \\
EVA & 0.450 & $522.391-2.92693 \mathrm{~T}$ & $0.02487+0.0001508 \mathrm{~T}-6.510 \mathrm{e}-6 \mathrm{~T}^{2}+4.728 \mathrm{e}-8 \mathrm{~T}^{3}-$ & 0.4995 \\
& & $+0.00410263 \mathrm{~T}^{2}$ & $1.362 \mathrm{e}-10 \mathrm{~T}^{4}+1.410 \mathrm{e}-13 \mathrm{~T}^{5}$ & \\
\hline
\end{tabular}


Darveaux's approach was taken to evaluate the solder's damage accumulation. Derived from the Paris power law of fatigue crack growth, the Darveaux approach considers the accumulation of inelastic strain energy density as a damage indicator for fatigue crack growth [6]. Accordingly, both crack initiation and crack growth are functions of the average inelastic strain energy density (plastic work) accumulated per loading cycle. In the current study, the two phases of failure were not differentiated, therefore only the total plastic work was considered as the metric for damage.

A model refinement was conducted to provide a level of confidence in our simulations. The $85^{\circ} \mathrm{C}$ thermal cycle, as described in the following section, was used for this purpose and simulations run for models of decreasing mesh size (coarse 3, to fine 0.5 ), or increasing degrees of freedom. The goal was to create a model that would provide accurate results within a reasonable computational time. For each model, eleven thermal cycles were simulated. By the $10^{\text {th }}$ cycle, the finest model was within $0.8 \%$ of its $11^{\text {th }}$ cycle's damage value. We found that the damage accumulated by each model decreased with each successive cycle and all models settled within 5\% of the finest model's final cycle value by the tenth cycle, Fig. 2 . While the coarsest model we considered rendered an $11^{\text {th }}$ cycle damage value within $5 \%$ of our finest model, we settled on the second coarsest model for the remainder of our study, Fig. 3. Furthermore, it was found that the solder joints on the bottom (backsheet side) of the cells accumulate damage at a rate more than 4 times faster than on the top of the cells, therefore; only the damage accumulated at the bottom of the middle cell was modeled and reported for the subsequent simulations.

\section{Simulations}

\section{Thermal Cycling}

Two types of simulations were conducted in this study: weather and thermal cycles. The thermal cycles represent interpretations of the thermal cycles designated in IEC 61215- Crystalline Silicon Terrestrial PV modules- Design qualification and Type Approval. All cycles have temperature ramp rates of $2{ }^{\circ} \mathrm{C} / \mathrm{min}$, a minimum temperature of $-40^{\circ} \mathrm{C}$ and 10 -minute cold and hot dwell times. The four cycles simulated are, therefore, designated by their hot dwell temperatures: $85,90,95$ and $100^{\circ} \mathrm{C}$. The damage reported for these cycles is the damage accumulated during the tenth successive cycle simulated.

\section{Weather}

A one-year history of module cell temperature was synthesized by examining meteorological data in each of the seven cities examined in this study. Ambient temperature, $T_{a m b}$, wind speed, WS, and total global irradiance, $E$, collected at one-minute intervals served as input into a steady state temperature model developed by King et al. to calculate cell temperature [7]:

$$
T_{\text {cell }}=T_{a m b}+E \cdot \exp (a+b \cdot W S)+E \frac{T}{E_{o}}
$$

The coefficients $a$ and $b$ were empirically determined for a glass/polymer backsheet module construction deployed in an open-rack configuration to be -3.56 and -0.075 , respectively [7]. $E_{o}$ is the reference solar irradiance of $1000 \mathrm{~W} / \mathrm{m}^{2}$ and $\Delta T$ represents the temperature difference between the cell and module at this reference irradiance. For an open-rack configuration $\Delta T$ was determined to be $3^{\circ} \mathrm{C}$; however, this offset temperature will be sensitive to racking method and module construction.

To capture transient behavior, an exponentially weighted moving-average (EWMA) filter with a time constant derived from experimental module temperature data was applied to the static model. Cell temperature at time step $t$ is calculated using:

$$
\left(T_{\text {cell }}\right)_{t}=\left(T_{\text {cell }}\right)_{t 1}+\left(T_{\text {cell }}\right)_{t}(1 \quad)
$$


where $\alpha$ is the EWMA gain, 0.8 . This method of synthesizing module cell temperature from meteorological data allows a more level comparison of location by removing the variability of specific module temperature measurements.

Simulations using this synthesized module cell temperature were run in one-month intervals. To account for the model's tendency to require a length of simulated time before settling to a constant damage rate, the first six days of each month were added to the end of the simulation. The damage calculated for each month, therefore, only considered the first six days the second time they were simulated.

\section{RESULTS AND ANALYSIS}

\section{Thermal Cycling}

An image illustrating the accumulation of inelastic strain energy within the modeled module's solder joints is presented in Fig. 4. The results for the thermal cycle simulations are presented in Fig. 5. The damage accumulated through one cycle with a maximum temperature of $85^{\circ} \mathrm{C}$ is $1.5 \mathrm{kPa}$ and increases to $11.3 \mathrm{kPa}$ with a maximum cycle temperature of $100^{\circ} \mathrm{C}$. This 7.4 times increase in damage is considerably higher than only the $\sim 50 \%$ increase that may have been expected from an empirical thermal fatigue equation such as Coffin-Manson or Engelmaier [8,9]. In anticipation that the temperature dependent elastic properties of the EVA may have contributed to this discrepancy, an additional set of simulations was performed while holding these properties at their $25^{\circ} \mathrm{C}$ values. The results of these simulations are also presented in Fig. 5 along with the Coffin-Manson predicted values and show an excellent agreement, suggesting that the large increase in damage with higher cycling temperature is likely due to the effective total loss of stiffness in the EVA layer at high temperatures and therefore the level of constraint imposed on the cell and solder joint.

\section{Weather}

The damage accumulated over the course of one year in the seven cities studied is presented in Fig. 6 . Chennai India accumulates the most damage at $38 \mathrm{kPa}$ while the other two cities characterized as Hot and Humid, Bhogat and Honolulu, accumulate considerably less damage at 10.2 and $11.5 \mathrm{kPa}$, respectively. When plotted as accumulated damage vs. time, as in Figure 6, the derivative of each curve represents the damage rate. This figure, therefore, additionally illustrates during which periods of time each city accumulates the most damage, and the difference in this damage rate between cities during similar periods. While Golden, Phoenix, Tucson and Chennai all exhibit a similar damage rate over the summer months, the period over which this rate persists is different for each city and directly results in their respective yearly accumulation. During the winter months, this rate drops to effectively zero for Golden, Phoenix and Tucson, while the damage rate of Chennai remains positive. Similar to Chennai, the damage rate of Honolulu and Bhogat also remains positive during the winter months, however at a much lower level. Bhogat uniquely appears to have its damage rate drop to zero during the summer months, which may correspond with a period of high precipitation. Sioux Falls, the only cold climate simulated, exhibits both the lowest damage rate during the summer months and the longest period during the transition and winter months when this rate drops to zero, resulting in its relatively small total damage accumulation of $4.5 \mathrm{kPa}$.

For the cities examined, the amount of simulated solder fatigue damage are not ranked with the mean monthly maximum temperature that dictates their climate designation, Table I, Fig. 7. Phoenix, the hottest of the cities examined, only accumulates $75 \%$ of the damage of Chennai, whose mean monthly maximum temperature is $1^{\circ} \mathrm{C}$ lower. And Golden, in a Temperate climate, accumulates more damage than both Bhogat and Honolulu, Hot climates both with higher mean temperatures.

\section{Understanding the weather}

To understand the specific influence weather has on solder damage accumulation we have developed an empirical model to calculate this value based on specific weather related input. This model is based on the well established Coffin-Manson and Norris-Lanzberg equations and constants and therefore shares several similar terms with these models, which calculate the acceleration factor between two regular and repeating 
thermal cycles [9]. Our model to calculate solder fatigue damage, $D$, from specific weather related input takes the form:

$$
D=C(T)^{n}(r(T))^{b} \exp \left(\frac{Q}{k_{B} T_{\max }}\right)
$$

where $\Delta T$ is the mean daily maximum cell temperature change, $T_{\max }$ the mean daily maximum cell temperature, $C$ a scaling constant and $Q$ and $k_{B}$ an activation energy and Boltzmann's constant, respectively. The temperature reversal term, $r(T)$, is the number of times the temperature history increases or decreases across the reversal temperature, $T$, over the course of a year. The scaling constant $C$ and the reversal temperature $T$ were used to fit this model to our simulated data, while the values of the exponents $n$ and $b$ and the activation energy $Q$ are shared with the Coffin-Manson and Norris-Lanzberg equations for $\mathrm{PbSn}$ eutectic solder, Table IV [9]. Fits were performed for weather input intervals of $1,5,30$ and 60 minutes.

\begin{tabular}{cccccc} 
Table IV & \multicolumn{1}{l}{} \\
\hline interval (min) & $C$ & $T(\mathrm{C})$ & $Q(\mathrm{eV})$ & $n$ & b \\
\hline 1 & 239.9 & 56.4 & 0.12 & 1.9 & 0.33 \\
5 & 249.9 & 56.9 & “ & “ & “ \\
30 & 344.1 & 55.8 & “ & “ & “ \\
60 & 405.6 & 54.8 & “ & “ & “ \\
\hline
\end{tabular}

A comparison between the result of our empirical model for the four weather input intervals and the 1minute FEM simulated damage is presented in Fig. 8. The inputs for the 1-minute empirical model, for the seven cities examined in this study, are presented in Table V. The fit of the 1-minute empirical model to the simulated calculations, closed symbols, is excellent as demonstrated by the points falling on a line of unity slope. The fit for the 5-minute input interval is also very good as are the 30- and 60-minute intervals, although the latter two would inaccurately promote Honolulu ahead of Golden as a more damaging location. The best fit of the empirical model without the reversal term, cross symbols, is also included in this plot to illustrate its influence on the damage calculation. This exercise shows that without the reversal term the model would underestimate the damage accumulated in the hotter cities and overestimate the damage accumulated in the cooler cities. Furthermore, the model would not accurately predict the rank of all cities, promoting Tucson ahead of Chennai and Honolulu ahead of Golden. The physical basis for the reversal term is to capture the number of loading cycles that significantly contribute to the fatigue of the solder joint. These loading cycles manifest as temperature reversals of the module while at a relatively high temperature of $56.4^{\circ} \mathrm{C}$, and therefore are likely due to clouding events on a hot, sunny day. Comparing the two hottest cities, Chennai and Phoenix: while their mean daily maximum temperature change is roughly the same Chennai has almost twice the number of reversals as Phoenix and therefore accumulates $\sim 35 \%$ more damage. Phoenix and Tucson have roughly the same number of reversals and almost identical mean daily maximum temperatures. However, Tucson's larger mean temperature change results in it accumulating almost $20 \%$ more damage than Phoenix. Comparing cities that accumulate lower amounts of damage, we find that while both Bhogat and Honolulu have mean temperatures over $12^{\circ} \mathrm{C}$ higher than Golden, they accumulate less damage due to both their lower mean temperature change and number of reversals. These instances illustrate how combinations of weather characteristics must be considered simultaneously in order to correctly assess a specific location's propensity for solder joint damage and the power and necessity of the empirical equation developed in this work. 


\begin{tabular}{lccc} 
Table V & $\begin{array}{c}T_{\max }, \text { mean daily } \\
\max \text { cell temp } \\
\left({ }^{\circ} \mathrm{C}\right)\end{array}$ & $\begin{array}{c}\Delta T, \text { mean daily max } \\
\text { cell temp change }\left({ }^{\circ} \mathrm{C}\right)\end{array}$ & $\begin{array}{c}r(56) \text {, number of } \\
\text { temp reversals } \\
\text { across } 56.4^{\circ} \mathrm{C}\end{array}$ \\
\hline city & 59 & 35.5 & 2060 \\
Phoennix & 53.4 & 34.7 & 1298 \\
Tucson & 53.2 & 37 & 1592 \\
Honolulu & 51.2 & 30.7 & 212 \\
Bhogat & 49.7 & 27.9 & 234 \\
Golden & 37.6 & 33.4 & 518 \\
Sioux Falls & 25.8 & 23.5 & 2 \\
\hline
\end{tabular}

\section{Accelerated exposure}

The damage accumulated through deployment can be directly compared to the damage accumulated through accelerated thermal cycling. We present the result of this comparison as the number of thermal cycles required to impart the same amount of solder fatigue damage as one year of deployment, or equivalent yearly thermal cycles, Fig 9. This plot presents the equivalent number of cycles for each of the seven cities for each of the four maximum cycling temperatures. Because of the direct relationship, the ranking and relative differences are identical to the accumulation of energy presented in Figs. 6 and 7. Chennai, the most damaging city, requires roughly 25 thermal cycles with a maximum temperature of $85^{\circ} \mathrm{C}$ to impart the same damage as a one-year exposure, while only seven such cycles are required for Bhogat, which is categorized in the same climate zone. The exponential increase in damage with maximum cycling temperature manifests in this plot as a dramatic decrease in the number of equivalent yearly thermal cycles. By increasing the maximum cycling temperature to $95^{\circ} \mathrm{C}$, the number of equivalent cycles for Chennai, for instance, drops to just eight.

\section{CONCLUSIONS}

The rate of solder fatigue damage was found to depend on three meteorological factors: mean daily maximum cell temperature, mean daily maximum cell temperature change and the number of temperature reversals across a characteristic temperature. An empirical formula was presented that used these three factors to accurately calculate the solder fatigue damage of the seven cities investigated in this study compared to FEM simulated results. This work demonstrated that the sole metric of a city's maximum ambient temperature, which often defines its climate zone, will not accurately rank their rate of solder fatigue damage accumulation.

The rate of solder fatigue damage accumulated through service was compared to the rate accumulated during accelerated thermal cycling. This comparison demonstrated that the most damaging city, Chennai, would require $\sim 630$ accelerated thermal cycles $\left(-40^{\circ} \mathrm{C}\right.$ to $\left.85^{\circ} \mathrm{C}\right)$ to accumulate an equivalent amount of damage as 25 years of service. The same analysis suggests sites like Phoenix and Tucson would require 470 and 560 cycles, respectively, for a 25 -year exposure. Increasing the maximum temperature of the thermal cycle increases the damage rate per cycle and therefore decreases the number of cycles required for an equivalent amount of solder fatigue damage. For instance, the 470 cycles with a maximum temperature of $85^{\circ} \mathrm{C}$ required to accumulate a 25-year exposure for Phoenix drops to only 154 cycles if the maximum temperature is increased just $10^{\circ} \mathrm{C}$ to $95^{\circ} \mathrm{C}$. This drastic increase in acceleration factor with increasing cycle temperature has tremendous utility in creating more efficient thermal cycling tests.

\section{Acknowledgements}

The authors would like to thank Atlas Testing Services, Atlas Material Testing Technology LLC, the National Institute of Solar Energy (NISE) and the Measurement and Instrumentation Data Center (MIDC) of the National Renewable Energy Laboratory (NREL) for furnishing the weather data used in this study. 
This research is based upon work supported in part under the Solar Energy Research Institute for India and the U.S. (SERIIUS) funded jointly by the U.S. Department of Energy subcontract DE AC36-08G028308 (Office of Science, Office of Basic Energy Sciences, and Energy Efficiency and Renewable Energy, Solar Energy Technology Program, with support from International Affairs) and the Government of India subcontract IUSSTF/JCERDC-SERIIUS/2012 dated 22nd Nov. 2012.

\section{REFERENCES}

[1] M. A. Quintana, D. L. King, F. M. Hosking, J. A. Kratochvil, R. W. Johnson, and B. R. Hansen, "Diagnostic analysis of silicon photovoltaic modules after 20-year field exposure," in Proceedings of the 28th IEEE PV Specialists Conference, Anchorage, Alaska, USA, 2000, pp. 1420-1423.

[2] N. Bosco, T. Silverman, and S. Kurtz, "The Influence of PV Module Materials and Design on Solder Bond Thermal Fatigue Durability," submitted to Journal of Photovoltaics, 2015.

[3] R. Dubey, S. Chattopadhyay, V. Kuthanazhi, J. John, B. M. Arora, A. Kottantharayil, et al., "All-India Suvery of PV Module Degradation: 2103," National Centre for Photovoltaic Reserach and Education Indian Institue of Technology Bombay National Insititue of Solar Energy 2013.

[4] D. C. Jordan, J. Wohlgemuth, and S. Kurtz, "Technology and Climate Trends in PV Module Degradation," in 27th European Photovoltaic Solar Energy Conference, 2012, pp. 2411-2415.

[5] G. Z. Wang, Z. N. Cheng, K. Beker, and J. Wilde, "Applying Anand Model to Represent the Viscoplastic Deformation Behavior of Solder Alloys," ASME Journal of Electronic Packaging, vol. 123, pp. 247-253, 2001.

[6] R. Darveaux, "Effect of simulation methodology on solder joint crack growth correlation," in Electronic Components and Technology Conference, 2000. 2000 Proceedings. 50th, 2000, pp. 1048-1058.

[7] D. L. King, W. E. Boyson, and J. A. Kratochvil, "Photovoltaic array performance model," Sandia National Laboratories SAND2004-3535, 2004.

[8] W. Engelmaier, "Generic reliability figures of merit design tools for surface mount solder attachments," Components, Hybrids, and Manufacturing Technology, IEEE Transactions on, vol. 16, pp. 103-112, 1993.

[9] K. Norris and A. Landzberg, "Reliability of Controlled Collapse Interconnections," IBM Journal of Research and Design, vol. 13, pp. 266-271, 1969. 


\section{FIGURE CAPTIONS}

Figure 1. Illustration of the 2D cross-sectional model of a generic flat plate PV module.

Figure 2. Normalized solder fatigue damage per thermal cycle with successive simulated ATC for four model mesh sizes.

Figure 3. Normalized solder fatigue damage vs model degrees of freedom. Higher degrees of freedom indicate a finer mesh size.

Figure 4. Graphical representation of the rate of accumulation of inelastic strain energy density within the solder joints of the modeled module. Presented image depicts the solder joints at the end of the cell in the middle of the module at the commencement of an accelerated thermal cycle cold temperature dwell. Both the joints on the top and bottom of the cell are included and demonstrate that energy accumulates more rapidly at the end of the bottom joint.

Figure 5. Solder fatigue damage accumulated through one thermal cycle as a function of maximum cycle temperature. Results for FEM simulations with temperature-dependent and -independent encapsulant properties as well as an empirical model fit.

Figure 6. Solder damage accumulated over the course of one year's service in the seven cities examined in this study.

Figure 7. Solder damage accumulated for one year's service vs. mean monthly maximum temperature.

Figure 8. Comparison of solder damage calculated through FEM simulation and modeled by Equation (3) for four weather input intervals. Cross symbols are the best fit of Equation (3) without the temperature reversal term.

Figure 9. Number of standard thermal cycles to cause damage equivalent to one year in the field vs. thermal cycle maximum temperature. 



Figure 1 


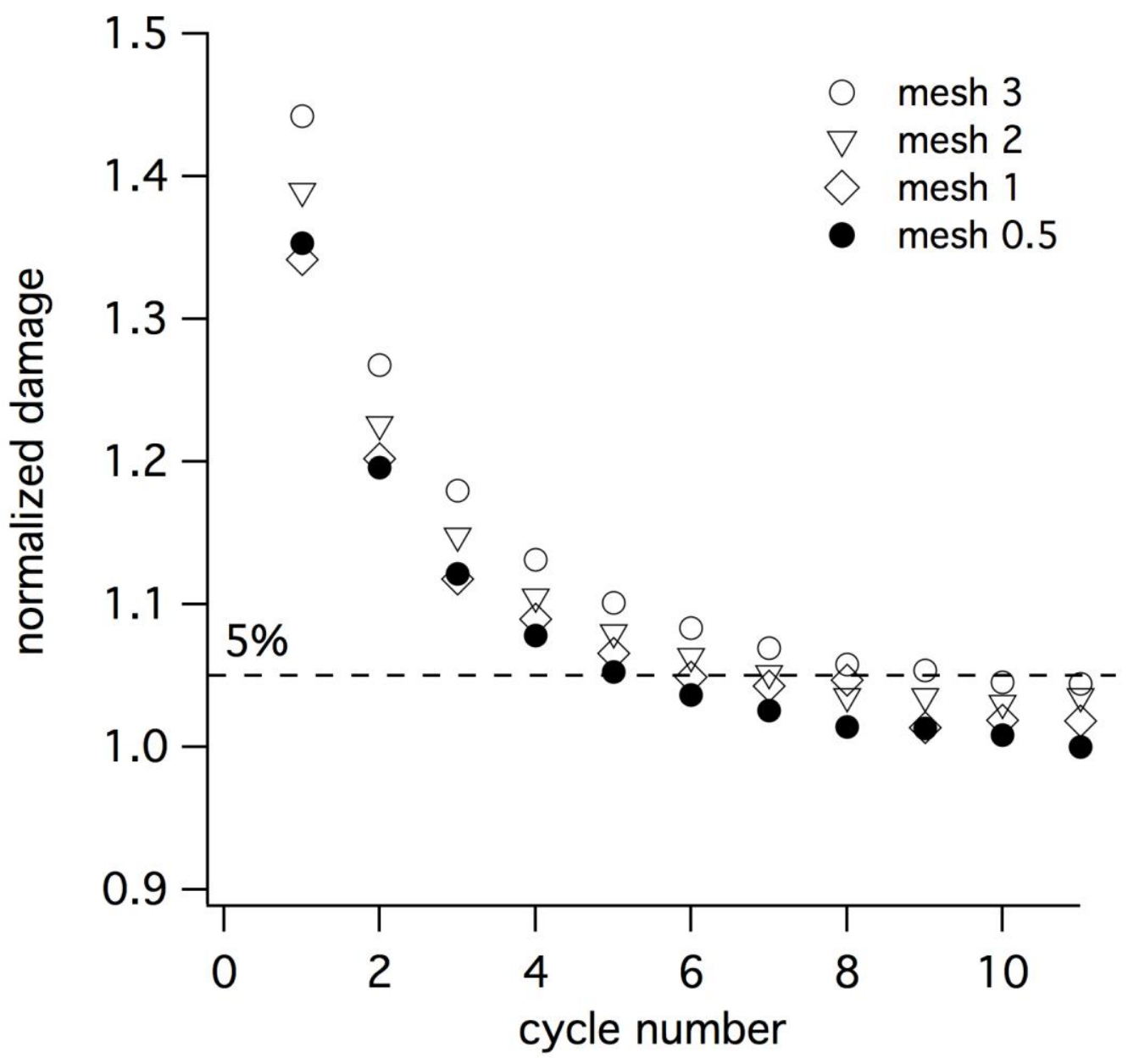

Figure 2 


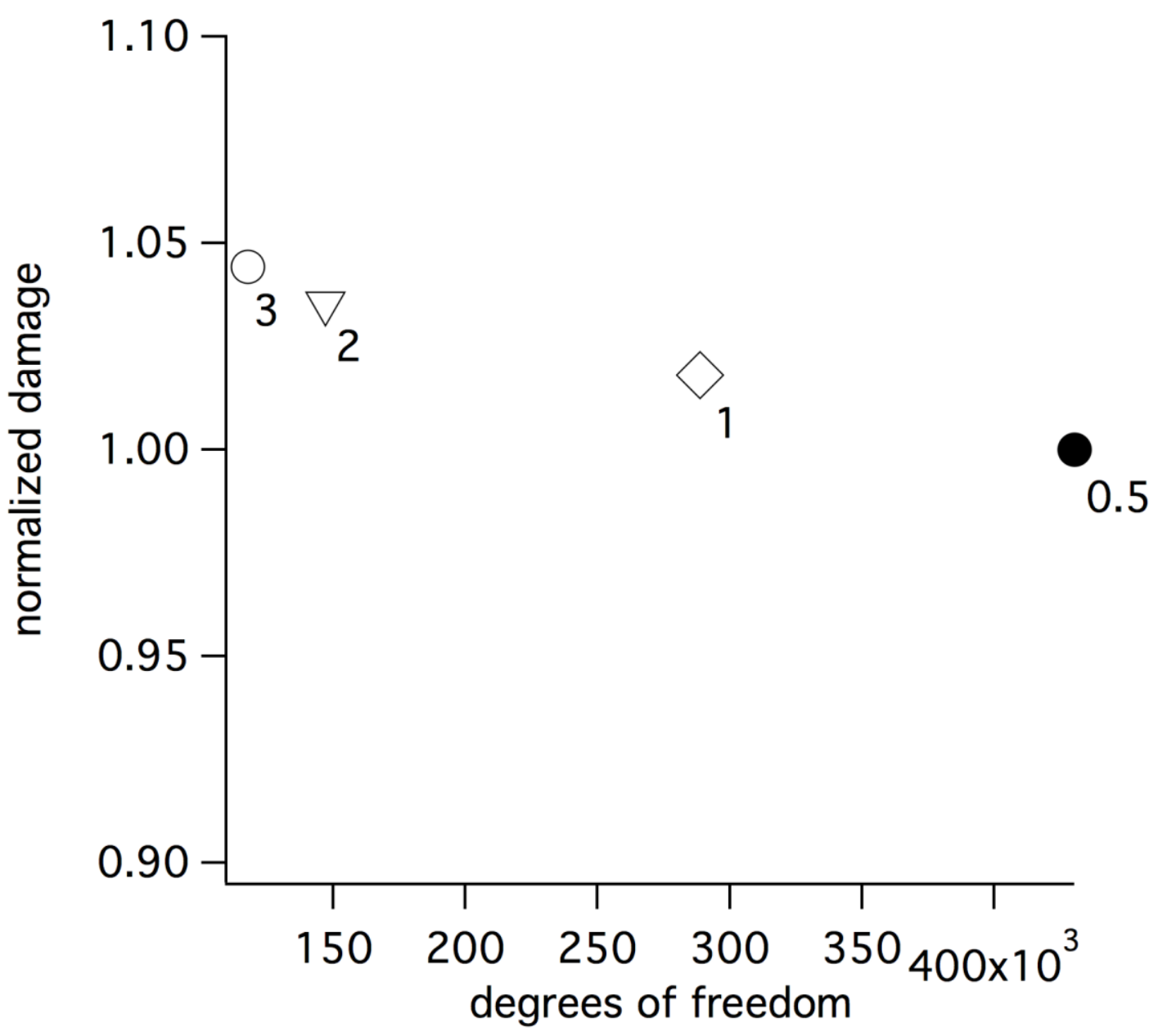

Figure 3 
Time $=54000 \mathrm{~s}$ Mesh

Surface: abs(solid.ectGp12*solid.sIGp12) (W/m $\left.{ }^{3}\right)$

$\Delta 222$

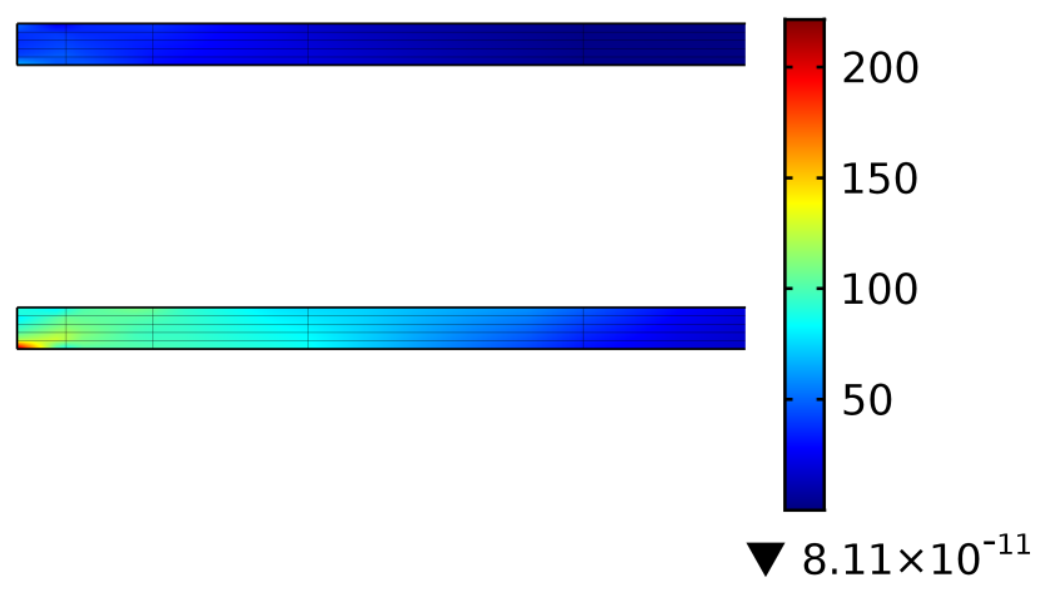

Figure 4 


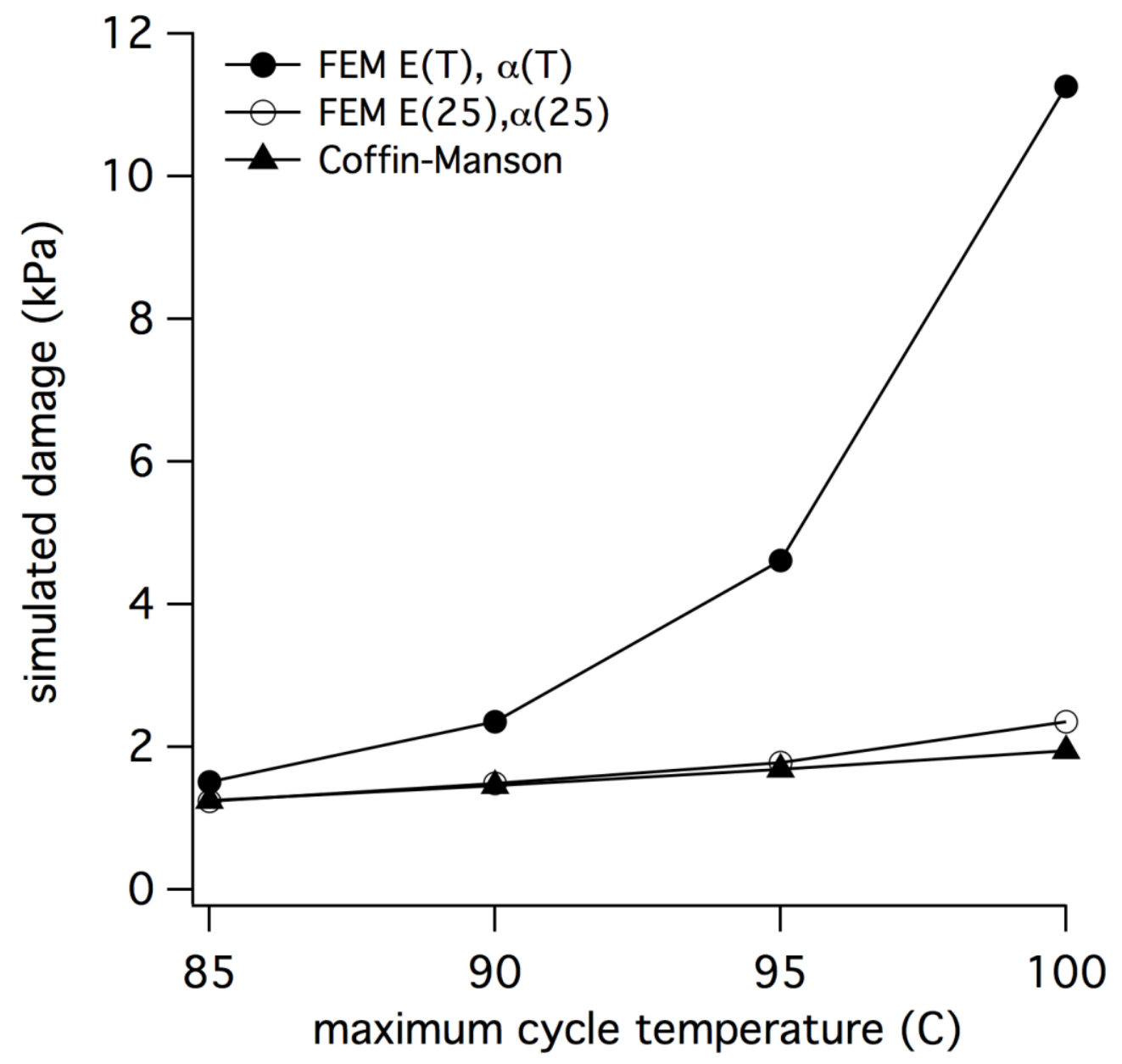

Figure 5 


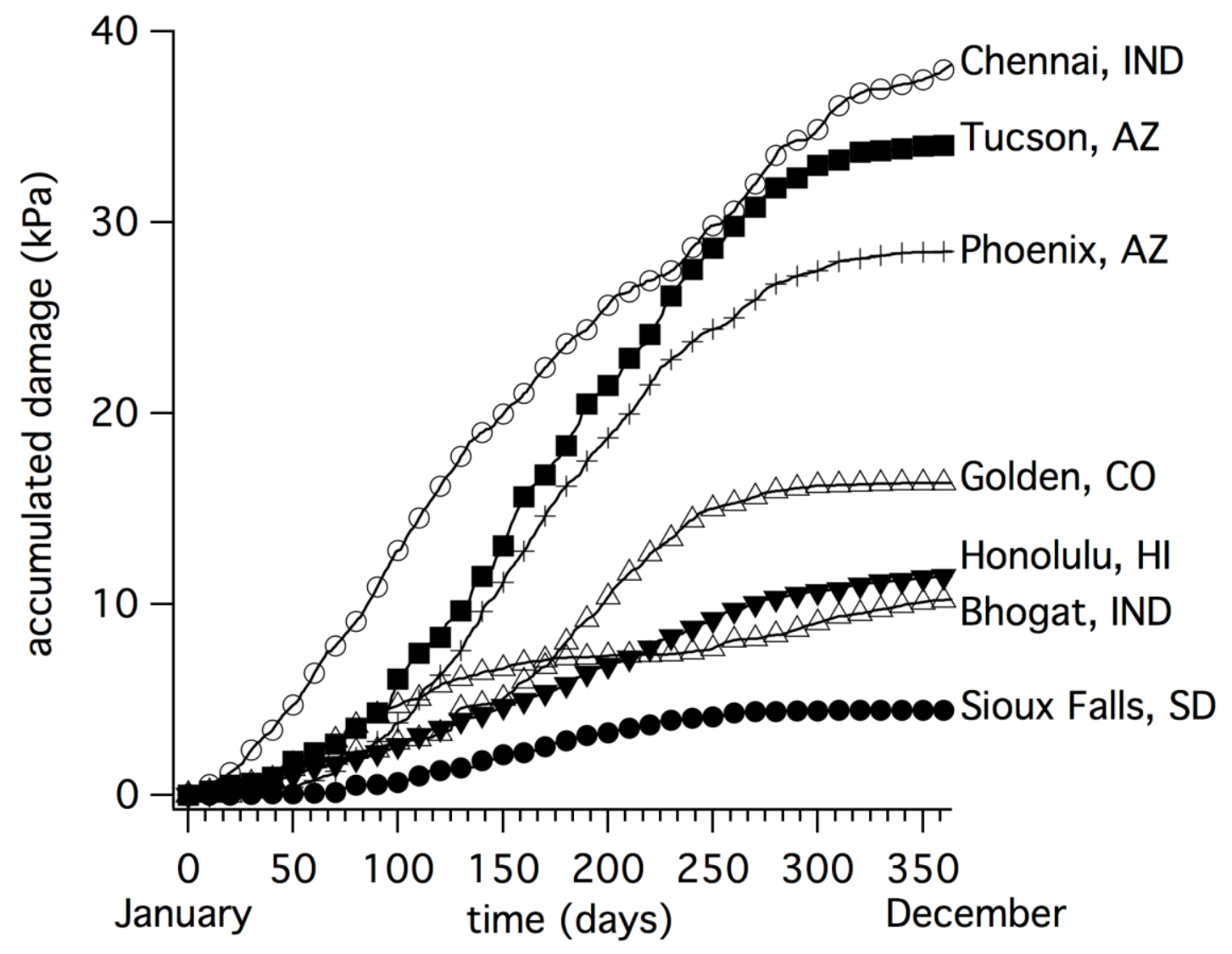

Figure 6 


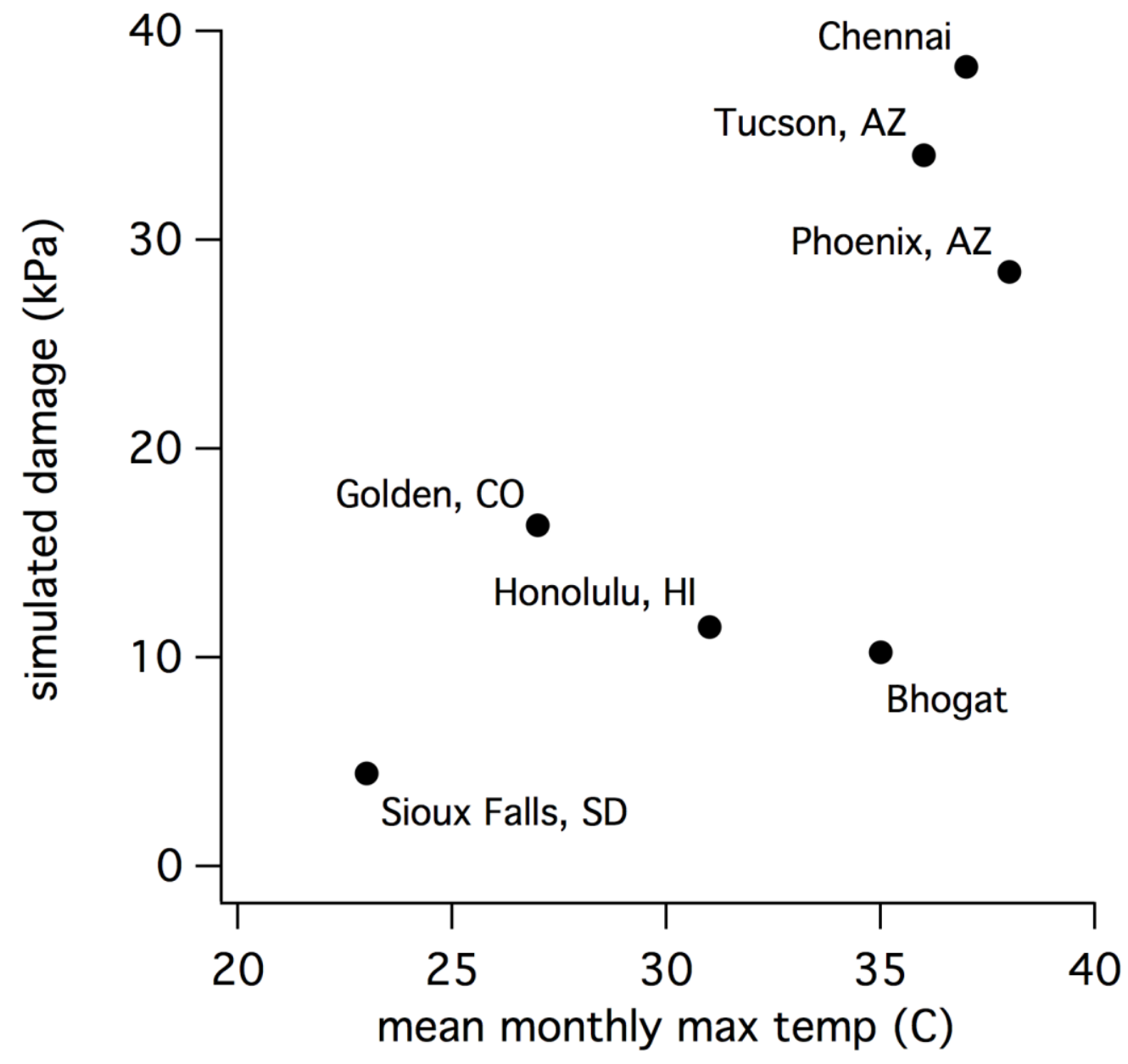

Figure 7 


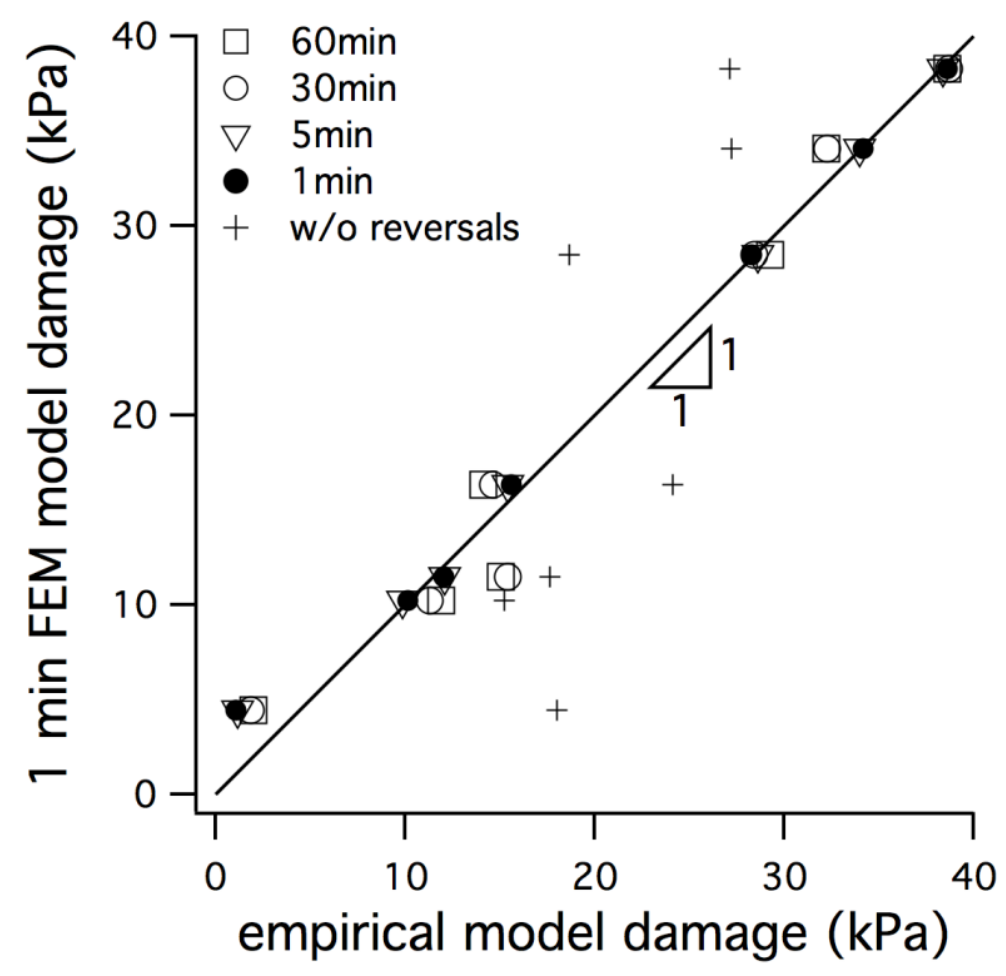

Figure 8 


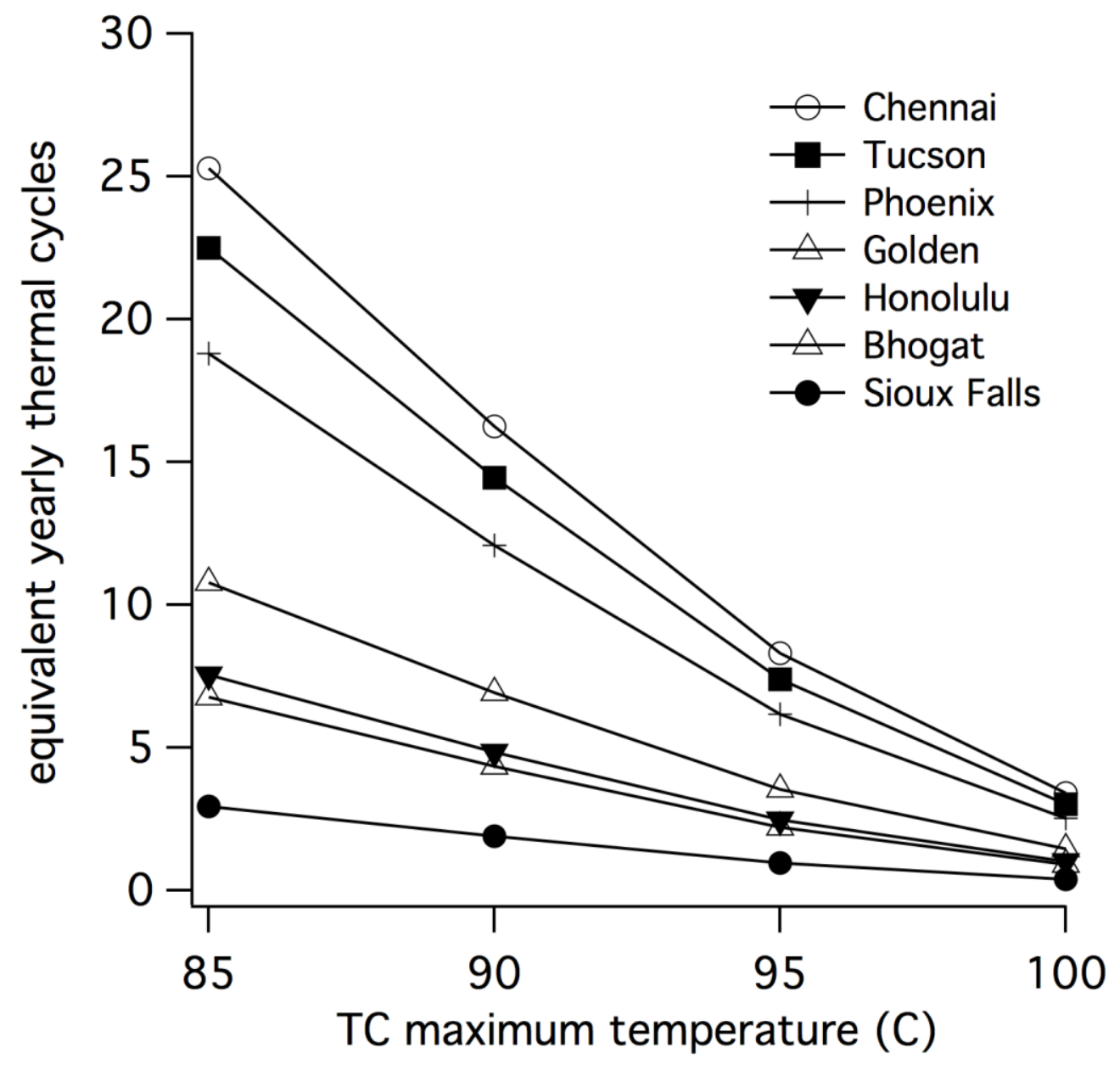

Figure 9 